\title{
Understanding the impact of breast cancer adjuvant endocrine therapy on cognitive function: a work in progress
}

\author{
Patricia A Ganz ${ }^{\star}, 1,2$ \\ ${ }^{1}$ Department of Health Policy \& Management, UCLA Fielding School of Public Health, Los Angeles, CA, USA and ${ }^{2}$ Center for \\ Cancer Prevention \& Control Research, Jonsson Comprehensive Cancer Center at UCLA, Los Angeles, CA, USA
}

Breast cancer is the most common cancer in women throughout the world and is associated with extended, long-term survival as a result of the effective application of chemotherapy and endocrine adjuvant therapies (Berry et al, 2005; DeSantis et al, 2016). The majority of breast cancers are hormone receptor positive and thus endocrine therapies play a critical role in reducing the risk of both distant and local recurrence of the primary cancer (Burstein et al, 2014). Surgical ovarian ablation was among the earliest approaches to adjuvant therapy in premenopausal breast cancer patients; however, the success of tamoxifen in treatment of metastatic breast cancer in pre- and postmenopausal women eventually led to its introduction as the main form of endocrine adjuvant therapy in premenopausal breast cancer patients in the latter decades of the twentieth century. Since that time, a variety of investigations have asked the question of whether or not ovarian function suppression (OFS) (either with surgery or with a gonadotropin-releasing hormone agonist) added to either tamoxifen or an aromatase inhibitor would improve the durability of disease-free survival and overall survival in premenopausal women (Goel et al, 2009). The recently completed SOFT and TEXT trials are the most ambitious studies to date to address this question (Pagani et al, 2014; Francis et al, 2015).

While improved survival is a central goal of adjuvant endocrine therapy, one must have respect for both the short-term and long-term complications of these treatments, especially in younger women, who are likely to have extended years of survival (Zwart et al, 2015). The short-term side effects of endocrine therapy include vasomotor, vaginal and sexual difficulties, with musculoskeletal complaints being more frequent with aromatase inhibitors (Bernhard et al, 2015; Ganz et al, 2016). Long-term risks include diminished bone density/fracture, thromboembolic events, uterine cancer, and potentially increased cardiac disease (Burstein et al, 2014). Until recently there has been limited examination of the potential for cognitive difficulties associated with initiation of endocrine adjuvant therapy (Bender et al, 2007, 2015; Buwalda \& Schagen, 2013; Ganz et al, 2014; Boele et al, 2015), as most earlier attention has focused on the potential for cognitive decline in association with chemotherapy (Ahles et al, 2012; Wefel et al, 2015).

There is emerging evidence that endocrine therapy in breast cancer patients is associated with cognitive difficulties, which is not surprising given the critical role of oestrogens in maintaining neural plasticity (Buwalda and Schagen, 2013). Numerous studies in healthy women demonstrate diminished verbal memory and verbal fluency in association with surgical or medical ovarian suppression (Zwart et al, 2015), as well as increased risk for dementia with premature menopause (Rocca et al, 2011, 2014). Decline in these same domains of neurocognitive function has also been noted in association with tamoxifen therapy (Boele et al, 2015). In their recent review, Zwart et al (2015) note that most studies of cognitive function in association with endocrine treatment of breast cancer have been small observational studies, and they call for more comprehensive assessments of the impact of this therapy on cognition. They also emphasise the importance of obtaining cognitive function assessments in clinical trials, as well as the critical need for long-term follow-up, as women with breast cancer are expected to have extended survival times in which cognitive decline might emerge as an important late consequence of treatment.

With this background, we need to consider the strengths and limitations of the report by Phillips et al (2016) in this issue of the British Journal of Cancer, describing an evaluation of cognitive function in women participating in the SOFT trial. The Co-SOFT substudy had an initial planned enrollment goal of 321 SOFT study participants who would be recruited at one of the 26 sites that were participating in the SOFT trial. The planned primary outcome for Co-SOFT was a comparison of objective cognitive function before the initiation of endocrine therapy and then 1 year later, across the 
three separate SOFT trial treatment groups. Additional questionnaires were administered to assess self-reported cognitive function, psychological distress, fatigue, insomnia and quality of life. Overall, this was a well-designed and comprehensive approach to assessing cognitive function/decline as part of an important randomised clinical trial.

Unfortunately, due to low accrual at the substudy participating centres and early closure of the parent trial, the sample recruited for Co-SOFT was substantially smaller than expected. The protocol was then revised to compare the tamoxifen sample to the combined OFS arms of the study, and we are told that the observed sample size (86 enrolled and 74 evaluable, in a two-group design) provided $80 \%$ power to detect an effect size of 0.76 with a two-sided $\alpha=0.05$. This is a large effect size for comparison of two endocrine therapies with overlapping toxicities and mechanisms of action. The authors do not report the original effect size that the study had been planned to detect, and it is likely that it was much smaller. Thus, the comparison presented in this analysis is underpowered to detect a likely difference of a small to medium effect between tamoxifen alone and the two OFS groups.

Additional concerns about the current report include the fact that while patients were randomly assigned to the three SOFT trial arms before being approached for Co-SOFT, the substudy inclusion required that patients could not have initiated endocrine therapy prior to randomisation (true for $\sim 70 \%$ of patients enrolled during the period of recruitment). However, use of endocrine therapy prior to randomisation was not a trial stratification factor, and thus those who were eligible for the CoSOFT study may not have been randomly allocated. Further undermining the likelihood that the final Co-SOFT sample reflects the trial random assignments is the fact that only 86 of 102 eligible patients joined the substudy during the recruitment period, and only 74 were assessed at two time points (before treatment and 1 year later). Thus, the treatment arms compared in this report reflect an observational cohort study design, with the sample being drawn from the parent SOFT trial.

The primary comparison in Co-SOFT was the change in the Composite Score of the CogState tasks, which was the measure used to assess neurocognitive function. Unfortunately, this test battery omitted the verbal fluency domain that is often affected by changes in oestradiol levels. Furthermore, a global composite score might not be as sensitive an indicator of cognitive dysfunction in this setting, since patients who experience cognitive changes with cancer therapy rarely exhibit global impairments, and have more often been noted to have subtle deficits in specific neurocognitive domains, such as verbal and visual memory, along with processing speed (Wefel et al, 2015). Although self-reported cognitive complaints were a secondary outcome in this study, the patients receiving OFS reported a substantially greater perceived decline in functioning compared to the tamoxifen-alone group. While the CogState composite score did not correlate with the self-reported functioning, in a recent study we found that women who initiated endocrine therapy for breast cancer with either tamoxifen or an aromatase inhibitor had worse performance on a cognitive assessment of psychomotor speed, and this was associated with specific aspects of verbal fluency (Ganz et al, 2014). The small sample size in the Co-SOFT study, as well as the focus on global assessment of cognitive function, likely limited the ability to detect true objective neurocognitive deficits associated with the use of OFS.

Nevertheless, Phillips et al should be congratulated for the effort they made to coordinate a comprehensive cognitive function assessment study within this important international adjuvant treatment trial. As with many ancillary studies, they are often difficult to conduct because of a lack of resources, and as a result their initiation is delayed and accrual may be limited. Future studies of cognitive decline must incorporate evaluations from inception of the trial so that adequate sample size and power are present to determine whether or not cancer treatments impact cognitive function. In particular, if self-reported cognitive function can reliably detect treatment-associated impairments, then this may be a more efficient way to universally assess cancer treatmentrelated cognitive impairment in the setting of randomised clinical trials.

\section{CONFLICT OF INTEREST}

Dr Ganz was an investigator participating in the SOFT trial.

\section{REFERENCES}

Ahles TA, Root JC, Ryan EL (2012) Cancer- and cancer treatment-associated cognitive change: an update on the state of the science. J Clin Oncol 30(30): 3675-3686.

Bender CM, Merriman JD, Gentry AL, Ahrendt GM, Berga SL, Brufsky AM, Casillo FE, Dailey MM, Erickson KI, Kratofil FM, McAuliffe PF, Rosenzweig MQ, Ryan CM, Sereika SM (2015) Patterns of change in cognitive function with anastrozole therapy. Cancer 121(15): 2627-2636.

Bender CM, Sereika SM, Brufsky AM, Ryan CM, Vogel VG, Rastogi P, Cohen SM, Casillo FE, Berga SL (2007) Memory impairments with adjuvant anastrozole versus tamoxifen in women with early-stage breast cancer. Menopause 14(6): 995-998.

Bernhard J, Luo W, Ribi K, Colleoni M, Burstein HJ, Tondini C, Pinotti G, Spazzapan S, Ruhstaller T, Puglisi F, Pavesi L, Parmar V, Regan MM, Pagani O, Fleming GF, Francis PA, Price KN, Coates AS, Gelber RD, Goldhirsch A, Walley BA (2015) Patient-reported outcomes with adjuvant exemestane versus tamoxifen in premenopausal women with early breast cancer undergoing ovarian suppression (TEXT and SOFT): a combined analysis of two phase 3 randomised trials. Lancet Oncol 16(7): 848-858.

Berry DA, Cronin KA, Plevritis SK, Fryback DG, Clarke L, Zelen M, Mandelblatt JS, Yakovlev AY, Habbema JD, Feuer EJ. Cancer ISurveillance Modeling Network C (2005) Effect of screening and adjuvant therapy on mortality from breast cancer. N Engl J Med 353(17): 1784-1792.

Boele FW, Schilder CM, de Roode ML, Deijen JB, Schagen SB (2015) Cognitive functioning during long-term tamoxifen treatment in postmenopausal women with breast cancer. Menopause 22(1): 17-25.

Burstein HJ, Temin S, Anderson H, Buchholz TA, Davidson NE, Gelmon KE, Giordano SH, Hudis CA, Rowden D, Solky AJ, Stearns V, Winer EP, Griggs JJ (2014) Adjuvant endocrine therapy for women with hormone receptor-positive breast cancer: American Society of Clinical Oncology Clinical Practice Guideline focused update. J Clin Oncol 32(21): 2255-2269.

Buwalda B, Schagen SB (2013) Is basic research providing answers if adjuvant anti-estrogen treatment of breast cancer can induce cognitive impairment? Life Sci 93(17): 581-588.

DeSantis CE, Fedewa SA, Goding Sauer A, Kramer JL, Smith RA, Jemal A (2016) Breast cancer statistics, 2015: convergence of incidence rates between black and white women. CA Cancer J Clin 66(1): 31-42.

Francis PA, Regan MM, Fleming GF, Láng I, Ciruelos E, Bellet M, Bonnefoi HR, Climent MA, Da Prada GA, Burstein HJ, Martino S, Davidson NE, Geyer CEJ, Walley BA, Coleman R, Kerbrat P, Buchholz S, Ingle JN, Winer EP, Rabaglio-Poretti M, Maibach R, Ruepp B, Giobbie-Hurder A, Price KN, Colleoni M, Viale G, Coates AS, Goldhirsch A, Gelber RD (2015) Adjuvant ovarian suppression in premenopausal breast cancer. N Engl J Med 372(5): 436-446.

Ganz PA, Petersen L, Bower JE, Crespi CM (2016) Impact of adjuvant endocrine therapy on quality of life and symptoms: observational data over 12 months from the mind-body study. J Clin Oncol 34(8): 816-824.

Ganz PA, Petersen L, Castellon SA, Bower JE, Silverman DHS, Cole SW, Irwin MR, Belin TR (2014) Cognitive function after the initiation of adjuvant endocrine therapy in early-stage breast cancer: an observational cohort study. J Clin Oncol 32(31): 3559-3567.

Goel S, Sharma R, Hamilton A, Beith J (2009) LHRH agonists for adjuvant therapy of early breast cancer in premenopausal women. Cochrane Database Syst Rev. (4). Art. No.: CD004562.

Pagani O, Regan MM, Walley BA, Fleming GF, Colleoni M, Lang I, Gomez HL, Tondini C, Burstein HJ, Perez EA, Ciruelos E, Stearns V, 
Bonnefoi HR, Martino S, Geyer Jr. CE, Pinotti G, Puglisi F, Crivellari D, Ruhstaller T, Winer EP, Rabaglio-Poretti M, Maibach R, Ruepp B,

Giobbie-Hurder A, Price KN, Bernhard J, Luo W, Ribi K, Viale G, Coates AS, Gelber RD, Goldhirsch A, Francis PA. TextInvestigators SInternational Breast Cancer Study G (2014) Adjuvant exemestane with ovarian suppression in premenopausal breast cancer. N Engl J Med 371(2): 107-118.

Phillips K-A, Regan MM, Ribi K, Francis PA, Puglisi F, Bellet M, Spazzapan S, Karlsson P, Budman DR, Zaman K, Abdi EA, Domchek SM, Feng Y, Price KN, Coates AS, Gelber RD, Maruff P, Boyle F, Forbes JF, Ahles T, Fleming GF, Bernhard J (2016) Adjuvant ovarian function suppression and cognitive function in women with breast cancer. Br J Cancer. (this issue).

Rocca WA, Grossardt BR, Shuster LT (2011) Oophorectomy, menopause, estrogen treatment, and cognitive aging: clinical evidence for a window of opportunity. Brain Res 1379: 188-198.
Rocca WA, Grossardt BR, Shuster LT (2014) Oophorectomy, estrogen, and dementia: a 2014 update. Mol Cell Endocrinol 389(1-2): 7-12.

Wefel JS, Kesler SR, Noll KR, Schagen SB (2015) Clinical characteristics, pathophysiology, and management of noncentral nervous system cancerrelated cognitive impairment in adults. CA Cancer J Clin 65(2): 123-138.

Zwart W, Terra H, Linn SC, Schagen SB (2015) Cognitive effects of endocrine therapy for breast cancer: keep calm and carry on? Nat Rev Clin Oncol 12(10): 597-606.

(c) (1) (5) (2) This work is licensed under the Creative Commons cc) ${ }_{\text {BY }}$ NC SA Attribution-Non-Commercial-Share Alike 4.0 International License. To view a copy of this license, visit http:// creativecommons.org/licenses/by-nc-sa/4.0/ 